\title{
O GÉNERO NO JORNALISMO EM TEMPOS DE RECESSÃO: COMO SE DÁ A REPRESENTAÇÃO MEDIÁTICA DAS MULHERES NUM CONTEXTO DE CRISE EM PORTUGAL
}

Juliana Souza

Centro de Estudos Sociais, Universidade de Coimbra, Portugal

\section{Resumo}

O presente artigo busca refletir sobre o silenciamento e a invisibilidade das mulheres, tanto na arquitetura macroeconómica da crise como na própria produção noticiosa adjacente. Começa-se por identificar em que medida as identidades das mulheres vêm sendo (re)produzidas e reforçadas pelo discurso institucional tal como hoje se encontra organizado na economia neoliberal. Por fim, faz-se uma análise reflexiva acerca da linguagem enquanto mecanismo regulador das formas convencionais de representação e de como os papéis socialmente expectáveis em relação às mulheres, tão ritualizados pelo jornalismo, delimitam a sua posição-de-sujeito na sociedade.

Palavras-chave: Estudos dos Media, identidades, crise financeira, linguagem.

\begin{abstract}
Gender in journalism in times of recession: how is the women's media representation in a context of crisis in Portugal

This article aims to reflect on the silencing and the invisibility of women in both the macroeconomic architecture of the crisis and in the adjacent news production itself. We begin by identifying the extent to which women's identities have been (re)produced and reinforced by institutional discourse as today is organized in the neoliberal economics. Finally, a reflective analysis is made about language as a regulatory mechanism of conventional forms of representation and how the socially expected roles towards women, as ritualized by journalism, delimit its position-of-subject in society.
\end{abstract}

Keywords: Media Studies, identities, financial crisis, language.

\section{Résumé}

Le genre dans le journalisme en période de récession: comment est la représentation médiatique des femmes dans un contexte de crise au Portugal

Cet article vise à réfléchir sur le silence et l'invisibilité des femmes dans l'architecture macro-économique de la crise et dans la production de nouvelles adjacente ellemême. Nous commençons par identifier la mesure dans laquelle les identités des femmes ont été (re)produit et renforcées par la façon comme le discours institutionnel est aujourd'hui organisé dans l'économie néolibérale. Enfin, une analyse réflexive est faite sur la langue comme mécanisme de régulation des formes classiques de représentation et de la façon dont les rôles socialement attendus envers les femmes, ritualisés par le journalisme, délimitent sa position-de-sujet dans la société.

Mots-clés: Études des médias, identités, crise financière, langage. 


\section{Introdução}

Ante a dramática situação de empobrecimento e de precariedade nas economias semiperiféricas da Europa, especialmente as que acabaram por implementar políticas de austeridade, o que se vê são classes trabalhadoras e sociais que respondem de forma mais aguda a esta conjuntura. Essa realidade pode ser mensurada, por exemplo, no significativo aumento dos índices de pobreza, de desemprego e de informalidade entre as mulheres, em termos comparativos com os homens. No último caso em concreto por exemplo, o de inatividade, o número chega a 46,2\% para as mulheres e 36,2\% para os homens (INE/Pordata, 2015).

Diante deste cenário de significativa clivagem financeira, o modelo económico neoliberal articula-se num ciclo vicioso onde os aspetos de género são constantemente negligenciados. Intensificam-se, assim, as normas e os papéis préexistentes e polarizados de género, contribuindo para um agravamento das iniquidades económico-sociais e das atuais dinâmicas sócio-laborais, logo, de um profundo retrocesso nas políticas e nas relações de igualdade de género. Os vetores de desigualdade conjugam-se com e determinam outros vetores excludentes, como os de segregação sexual em diversos níveis, nos quais a população feminina é económica e socialmente mais vulnerável inclusivamente a marginalização das mulheres nas prioridades económicas e na vida pública (Casaca, 2012; Ferreira, 2014; Karamessini, 2014).

Muito embora as mulheres conquistem diariamente novos espaços, novas funções e maior participação no mercado de trabalho, ainda representam uma minoria no centro das decisões políticas, já que são parte indissociável de um sistema organizado a partir de uma histórica dicotomia: as relações sociais de produção e de reprodução que fazem equivaler a produção à masculinidade e a reprodução à feminilidade. Nesta lógica dicotómica de dominação/subjugação, as desigualdades políticas e económicas vividas pelas mulheres reafirmam padrões de constituição de feminilidade/masculinidade (Reinharz, 1992: 147). A ação política das mulheres na política portuguesa, um espaço tradicionalmente reservado aos homens, e, portanto, não expectável, logo inaceitável, para as mulheres ${ }^{1}$, é representativa dessa dicotomia. No poder autárquico português, por exemplo, em 2013, era de apenas 7,5\% (INE, Dossiê temático Género).

Neste debate, é importante ter em mente que ao repensar o género enquanto prática socialmente construída, a estrutura macroeconómica de um país contribui para a construção de significados simbólicos em torno de modelos hegemónicos de masculino e de feminino (Gauntlett, 2004; Bordo, 1993) nas mais

\footnotetext{
Como reforça Gaye Tuchman (2009), quando a representação mediática das mulheres se refere ao contexto político, contexto em que a inferioridade do seu estatuto social e profissional se constrói por meio da sub-representação e da «trivialização» das suas atividades, no caso, políticas, mesmo quando, como hoje, esse quadro é composto por um número muito maior de mulheres.
} 
diversas esferas sociais, inclusive na laboral. A recessão económico-financeira e a austeridade partem deste mesmo processo de constituição social, por serem patriarcais na sua essência e por negligenciarem os aspectos principais de género. Representativas desta profunda assimetria de género na sociedade são a própria configuração e divisão do trabalho e das transferências sociais, em que se verifica uma significativa segregação e vulnerabilidade social das mulheres.

Considerando que os níveis de bem-estar e de proteção social continuam a representar uma efetiva via de integração social das mulheres, tanto no mercado de trabalho como no espaço público, com a retração do Estado, e os subsequentes cortes nos apoios sociais, essa marginalização sedimenta-se, comprometendo sistematicamente, neste ciclo, a sua autonomia económica, financeira (Karamessini \& Rubery, 2014; Muñoz \& Madroño, 2011) e política ${ }^{2}$. Como se vê documentado no Relatório da Campanha Feminista Anti-Austeritária, de $2013^{3}$ :

os cortes nas despesas sociais do Estado pressupõem o incremento do trabalho doméstico e do cuidar não-remunerados, em geral, a cargo das mulheres [...] esta insuficiência de recursos traduz-se na falta de poder que vulnerabiliza, subordina, oprime e impede o acesso à cidadania ativa e plena (2013: 5/6).

A ausência de políticas públicas orientadas para a integração económica, social e política das mulheres passa a ser determinante para o agravamento da crise social, sobretudo em anos de austeridade. Um dos impactos mais evidentes, conforme ilustra Jill Rubery, é «o encorajamento das mulheres a deixar o mercado de trabalho ou a assumir um emprego de baixa remuneração» em alturas de recessão (2014: 32).

O discurso institucional tem procurado naturalizar as medidas austeritárias e de ajuste fiscal, apresentando-as como um processo natural e inevitável da economia, no qual a consagração do livre-mercado e da meritocracia sobressaem ${ }^{4}$ e, assim, as obrigações inerentes ao Estado (social), como as despesas sociais, são ocultadas.

Em Portugal, esta particularidade do modelo económico neoliberal tem sido cada vez mais concreta e recorrente. Por exemplo, o Estado-providência, ineficiente e incapaz de subsidiar as despesas sociais, nomeadamente em tempos de crise, obriga os sujeitos a recorrer a políticas familiaristas e assistencialistas que, como sublinha o Relatório acima referido, submetem os «direitos individuais a

2 O comprometimento da autonomia financeira das mulheres, pela óptica de Boaventura de Sousa Santos (2011), em parte decorrente da desigualdade social, implica o agravamento da discriminação contra as mulheres.

3 Documento organizado pela UMAR (União Mulheres Alternativa e Resposta) e apresentado no I Encontro Nacional da Iniciativa por uma Auditoria Cidadã «As crises não pagam dívidas».

4 Como veremos mais adiante, a retórica pós-feminista em torno da recessão financeira é demasiada utilizada para naturalizar (e também consolidar) o ideário neoliberal de consumo de massa. 
um modelo patriarcal, heteronormativo, único e exclusivo, dificultando verdadeiros percursos emancipatórios das mulheres e demais pessoas» (2013: 6). Novamente aqui, a autonomia das mulheres é posta em causa uma vez que o reforço do seu papel subsidiário da família, compromete a desvinculação da esfera doméstica, do trabalho não-remunerado e de áreas-chave da cidadania reflexos, por sua vez, das convencionais relações de género ${ }^{5}$.

O mercado de trabalho português, tanto na sua estrutura como na sua dinâmica, representa um importante indicador de como as relações de género estão configuradas numa economia condicionada pelas políticas de intervenção do FMI. Com a contração económica, agravada pela obrigatoriedade do cumprimento dos critérios estabelecidos no Memorando de Entendimento acordado com a Troika, assinalo a expansão do nível de precariedade no emprego em Portugal. De acordo com os dados de 2009 da CET, cerca de 41,3\% dos respondentes têm vínculos passíveis de traduzir condições de alguma precariedade - adicionando-se, à ausência de contrato (12,3\%), os contratos a termo certo $(20,4 \%)$, os contratos a termo incerto $(6,9 \%)$ e a categoria recibos verdes cumprindo horário $(1,7 \%)$. As consequências sociais para as mulheres são ainda mais graves, uma vez que, como temos dito, a estrutura económica apresenta-se patriarcal em sua essência. Tais como: a expansão da economia informal feminina e de formas mais precárias de emprego (Ferreira, 2014), a maior fragilização dos vínculos contratuais, a insegurança de emprego, o trabalho a tempo parcial involuntário, o desemprego e o desemprego de muito longa duração (Casaca, 2012: 02), a estagnação profissional, a deterioração do mercado de trabalho feminino (Ferreira, 2014), bem como a perda ou a redução das transferências sociais.

Ao discutirmos as crises económicas e o impacto que recai sobre as mulheres, é preciso ter em conta que a economia, particularmente nestes momentos de clivagens político-económicas, como já referido, ancora-se numa particular fluidez dos vínculos de contratação da mão-de-obra. Deste modo, somado aos cortes nas despesas sociais, a liberalização do mercado e a posterior flexibilização das relações laborais (Muñoz e Madroño, 2011; Casaca, 2012) permitiram às empresas atuar em conformidade com a demanda do mercado e, assim, empregar conforme os recursos e a flexibilidade disponível (Rubery, 2014).

Nestes termos, sempre coube às mulheres o papel de «exército de reserva» no funcionamento da economia de mercado ${ }^{6}$. Baseando-se na análise que as teorias feministas marxistas fazem das lutas de classe, Muñoz e Madroño procuram demonstrar que, devido sobretudo à fluidez do mercado e dos vínculos laborais que daqui se desdobram, as mulheres constituem uma reserva potencial de tra-

5 Um exemplo deste processo pode ser atribuído ao fenómeno da feminização da força laboral feminina. Ver em Casaca, Sara (2012) e Ferreira, Virgínia (2014).

6 Muñoz e Madroño (2011: 117) complementam esta questão da mão-de-obra flexível: «são as mulheres as que fornecem o maior grau de flexibilidade na economia informal na sua interação com a formal». 
balho disponível a qualquer momento, sendo mobilizadas consoante a demanda do mercado de trabalho. Ou seja: contratadas em épocas de crescimento e despedidas em épocas de recessão (2011: 117) - em grande parte devido à flexibilidade danosa ${ }^{7}$ de que fala Sara Falcão Casaca (2012).

Ao pensar sobre a presença das mulheres no modelo liberal de hoje, nesta perspectiva de impulsioná-las dentro e fora do mercado de trabalho em respostas às mudanças económicas, tornar-se-á cada vez mais evidente como o processo de segregação no qual as mulheres estão historicamente inseridas pode ser o escopo para o entendimento das diferenças de género no impacto das alterações macroeconómicas ${ }^{8}$. No fundo, importa observar esta segregação como mais um reforço das normas e dos papéis tradicionais e estanques de género de (de)limitar a posição-de-sujeito das mulheres. Mas, acima de tudo, como este novo modus operandi tem implicado uma profunda transformação das relações sociais de sexo/género, sobretudo em contextos de crise. Assim, é notório que a austeridade marginaliza a posição-de-sujeito das mulheres na sociedade, subordinando e oprimindo-as, estimulando-as a um retorno para os papéis tradicionais de género.

\section{O género mediático da recessão: uma oposição à realidade}

Muito embora as evidências sejam profundamente decisivas para o entendimento de que a crise económica com que hoje Portugal se confronta tem determinado a integração e a posição das mulheres na economia e na sociedade, a ofensiva ideológica por parte do poder institucional, ao desconsiderar o caráter social da recessão no debate público, contribui para um entendimento obtuso das reais implicações da crise na vida quotidiana. Os governos neoliberais e conservadores da austeridade, inaptos a garantirem melhores níveis de integração social por meio do bem-estar e da proteção social, produzem diferentes retóricas políticas e jornalísticas para se direcionar a crise, nas quais a análise social da recessão é frequentemente omitida.

Num ambiente marcado pela instabilidade e pela tentativa de manipulação da opinião pública, o campo comunicacional, em particular neste contexto de grave recessão financeira, é, igualmente, submetido a uma lógica reguladora, baseada em fórmulas e modelos rotinizados, num constante jogo entre a lingua-

7 A perspetiva neoliberal da flexibilização das economias enquanto a solução para as dificuldades de competitividade das empresas e do próprio Estado, com a proposta de dinamizar a economia como um todo, segue o que Sara Casaca chama de flexibilidade danosa, prática que se apoia em baixos custos salariais, no emprego precário, instável e inseguro no seio das relações laborais.

8 Sobre esta questão, Jill Rubery (2014) aponta a relação «género, recessão e austeridade», como social e culturalmente construída, já que tais diferenças de género serão determinadas pelo seu contexto, bem como pelas suas instituições. 
gem do dito e a do não dito 9 . Assim, nesse processo de controlo social, a principal estratégia é a da (contínua) distração que, de acordo com Noah Chomsky, "consiste em desviar a atenção do público dos problemas importantes e das mudanças decididas pelas elites políticas e económicas» $(2013)^{10}$.

Essa lógica inscrita nas notícias, que determinará, por sua vez, as normas culturais e sociais por meio da transmissão de valores, ideologias e símbolos, opera segundo estratégias de agenda-setting que são, por sua vez, condizentes com os interesses comerciais (Lemieux, 2000; Biroli, 2010) do veículo de comunicação e de seus clientes. Assim, é possível considerar e reafirmar que os media não são um reflexo da realidade (Fairclough, 1999), mas sim "propostas de leitura da realidade» (Cabo et al., 2007), ou ainda, parte indissociável do processo de construção de significados, determinando posições-de-sujeito, categorizando ações e legitimando as relações de poder. Logo, não há verdades nem «neutras» nem «objetivas» como se pretende que estas sejam entendidas.

Esse panorama se reflete também na própria ofensiva ideológica dos media. Logo, a questão dos padrões de constituição de feminilidade/masculinidade enquanto uma das mais eficazes manifestações do poder patriarcal volta aqui a contar. Como frisa Sara Magalhães (2011), o ideário de feminilidade desempenha um notório mecanismo de "orientação de ação e de identificação de possíveis posicionamentos, práticas e subjetividades» no que se refere aos papéis e funções socialmente expectáveis para as mulheres. Este arquétipo emerge, sobretudo, por meio da linguagem mediática e das suas construções discursivas que reafirmam modelos, posicionam as mulheres no espaço público e no privado e, desse modo, categorizam as suas ações.

Como consequência de toda esta organização, em alturas de contração económica, nas quais a retração nos níveis de consumo interno e de liquidez das famílias contribui para o arrefecimento económico, as propostas de comportamento social para as mulheres voltam-se, maioritariamente, para os seus papéis convencionais de género. Em termos de representação social das mulheres como frisa o já referido Relatório da Campanha Feminista Anti-Austeritária, agrava-se a desigualdade e, como consequência, acentua-se «a colagem cultural das mulheres à esfera da reprodução» (2013: 05). Partindo-se do pressuposto de que o ideário pós-feminista ${ }^{11}$ (braço armado do jornalismo) trabalha com questões que vão ao encontro do consumo de massa tão celebrado pelas práticas neoliberais, a imprensa sedimenta os comportamentos inerentes a esta estrutura patriarcal.

Em seu amplo trabalho sobre as representações de género nas revistas ditas femininas, especialmente nas dirigidas ao público juvenil no Reino Unido, Rosa-

\footnotetext{
9 Esta estratégia dificulta os verdadeiros percursos emancipatórios (2013: 06) e as forças de resistência e de contestação que são próprios, por exemplo, dos feminismos.

10 Ver em https://colectivolibertarioevora.wordpress.com/2015/07/03/chomsky-as-10-estrategiasde-manipulacao-mediatica/comment-page-1/\#comment-2357. Último acesso em Julho de 2015.

11 Commumente conhecido como feminismo neoliberal.
} 
lind Gill (2007) não deixa de frisar a organização editorial (de conteúdos jornalísticos e publicitários) das publicações segmentadas e dirigidas às mulheres, logo, a padronização da linguagem jornalística enquanto um mecanismo basilar na regulação das lógicas identitárias pós-feministas e, portanto, nas construções sociais das mulheres que daí emergem. Maria João Silveirinha (2011) e Cláudia Álvares (2012) compartilham da ideia de que a sistematização do conteúdo a que estas revistas estão sujeitas contribui, com efeito, para a tipificação dos acontecimentos e dos sujeitos segundo critérios que organizam as normas sociais e definem os papéis sexuais e as representações convencionais de género na sociedade. Acerca daqueles que acabam por representar os padrões de género permitidos na cobertura noticiosa, Silveirinha (2011) ainda reforça o impacto que a padronização e a consequente segmentação exercem sobre a forma de ver as mulheres na sociedade. Assim, segmentar a notícia é arrumar a sociedade em categorias que promovam a diferença, apaguem as distinções e, assim, fomentem o consumo voltado para as mais variadas «necessidades».

Considerando o jornalismo parte indissociável deste processo de construção de significados, ao (re)produzir novas propostas de comportamento social, parcialmente determinadas por considerações editoriais e socioeconómicas (Lemieux, 2000; Tuchman, 2009; Biroli, 2010), os conteúdos mediáticos «contribuem para a perpetuação da ordem social estabelecida», tal como reforçam Arús et al. (2000: 22). Esta visão essencialmente comercial dos media coaduna-se com o que Tuchman denominou de «aniquilação simbólica» das mulheres, em que sobressaem a perpetuação de uma ordem (patriarcal) por meio de modelos de subjetividades e de mecanismos de (sub)representação, sobretudo quando nos referimos a um nicho ${ }^{12}$ muito específico do mercado, o dito «feminino».

Esta abordagem conduz a algumas interpretações que se versam sobre os dois vectores de observação da produção discursiva dos media em torno do ideal de feminilidade: o da repetida celebração do ideal de beleza e o da construção narrativa que fomenta nas leitoras um sentimento de incompletude (Gauntlett, 2004; Bordo, 1993), os quais, atuando em conformidade com a construção subjetiva deste ideário, impulsionam o consumo de massa junto ao target feminino. Deste modo, ser feminina nunca foi tão aclamado pela comunicação social, especialmente nessa altura de contração económica ${ }^{13}$. No contexto português de austeridade, essa estratégica de controlo e de formatação social pode ser observada tanto nas revistas segmentadas e dirigidas às mulheres, como também nos media generalistas, ethos, por excelência, do debate público sobre a crise económica.

Nota-se então o reforço da construção economicista dos referenciais hege-

Gaye Tuchman define nicho como "posição social ocupada por um determinado meio ou empresa de media, descrita pelas características demográficas daqueles que a ocupam». In «Media, Género, Nichos» (2009: 16).

13 Uma prática que se intensifica quando nos referimos às revistas generalistas dirigidas ao público dito «feminino». 
mónicos de feminilidade sob as lógicas identitárias de consumo patriarcais. Assim, apropriando-se de uma retórica pós-feminista claramente genderizada que busca celebrar a liberalização sexual e a (pseudo)autonomia económica e financeira enquanto fatores decisivos para esta nova representação social das mulheres -, nota-se que as noções em torno do conceito de feminilidade nunca estiveram tão em evidência. Importa referir que nessa cultura popular da recessão, o pós-feminismo fortalece as mesmas ambivalências que sempre procuraram silenciar esse movimento político, actuando enquanto modalidades sofisticadas de um anti-feminismo ${ }^{14}$. Tais ambivalências reforçam, por um lado, as convencionais referências material e sexual no domínio da sexualidade, na autonomia do sujeito-mulher e na sua liberdade de escolha; e, por outro, "o seu potencial para romper a estabilidade das normas geracionais» (2014: 23), subvertendo uma certa ordem, como forma de atrair o seu público para as práticas pós-feministas. O que se verifica hoje, sobretudo na cultura popular da recessão, é uma tentativa de reduzir os feminismos, numa apropriação astuta de muitos dos seus ideais emancipatórios, às práticas convencionais de consumo (Álvares, 2012).

Contudo, considerando que a agenda neoliberal e pós-feminista (Walby, 2011) trabalha com objetivos que oscilam entre propósitos contraditórios, esta representação ora declina para um discurso de cariz progressista ao incentivar as mulheres à exploração desta feminilidade (em oposição à masculinidade, por via de regra), obscurecendo as assimetrias de género; ora destitui-as da carga emancipatória e de empoderamento por meio de um discurso convencional profundamente ancorado em referenciais ontológicos.

Neste contexto de práticas reguladoras de consumo, a partir destas evidências e em convergência com o que foi observado por David Gauntlett (2004) e Susan Bordo (1993) acerca dessa normatividade que sempre marcou a história das mulheres, o sentimento de incompletude e de otimismo passam a ser um denominador comum. Negra e Tasker (2014) chamam a atenção para o facto de a cultura popular da recessão eleger e redefinir os papéis das mulheres em plena crise, sobretudo o de consumidora. É sobretudo por esta razão que a análise do caráter social da recessão é frequentemente omitida pela imprensa.

Tendo em conta essas evidências, gostava de sugerir que esse processo de produção noticiosa sobre a crise para as mulheres, ao atuar em consonância com propósitos económicos e políticos, também traduz a realidade de subvalorização e de silenciamento das mulheres no espaço público. Isso possibilita desconstruções em torno das relações de poder que se sedimentam nesse modelo político-

14 Exemplo notório da abordagem do anti-feminismo sofisticado (McRobbie, 2011), a prática - de construções negativas que a linguagem neoliberal operacionaliza com relação aos «velhos feminismos» - está muitas vezes associada ao sexismo ainda vigente, sobretudo em sociedades profundamente marcadas por práticas conservadoras e discriminatórias. Isto está muitas vezes associado à ideia, reiterada pelo discurso institucional, de que os feminismos já caíram em desuso. 
económico que é o neoliberalismo e o jornalismo. Nancy Fraser (2009) construiu um argumento persuasivo em torno desta arquitetura macroeconómica e das novas representações sociais das mulheres e concluiu que este modelo cria os mecanismos necessários para atribuir novos significados e sentidos às práticas sociais quotidianas, inclusivamente as práticas de consumo como acima referido.

No que se refere aos papéis atribuídos às mulheres durante uma altura de contração económica, vemos claramente a (re)produção de paradigmas que tanto contemplam uma aparente crítica à economia política - no caso concreto de Portugal, a política de governação austeritária - como as novas aspirações em torno da superação, por meio do discurso pós-feminista da meritocracia ${ }^{15}$ ou de um certo empoderamento, de uma crise conjuntural. $\mathrm{O}$ impacto desse discurso pode ser traduzido na própria omissão, por parte da imprensa, de questões basilares no que respeita ao retrocesso na igualdade de oportunidades e reforço das normas de género que a crise provoca, como o retorno das mulheres à esfera doméstica - seja pela insuficiência de meios dos agregados familiares (e a economia que esta decisão possa proporcionar), seja pelas novas «oportunidades» que daí advêm. Como Negra e Tasker (2014: 04) exemplificam, a recessão é veiculada pelos media como uma oportunidade de crescimento e de recuperação económica.

Nessa redefinição de papéis, o modelo tradicional das relações de género volta a ser explorado pela retórica política e jornalística, especialmente em competências circunscritas à esfera privada, revestidas de «novas economias domésticas» (Negra e Tasker, 2014: 08). Para além dessas representações, as autoras apontam outras que se destacam na cultura popular da recessão, das quais sublinha-se: 1) o trabalho autónomo e o doméstico como modelo de superação da força laboral feminina; 2) as novas categorias de consumo e de produção e 3) as novas categorias de trabalho, como o estágio e o trabalho a tempo parcial.

São recorrentes, por exemplo, o velho discurso dicotómico da ação (na esfera pública) para os homens e da passividade (no âmbito privado) para as mulheres no combate à crise, em que sobressai toda uma simbologia em torno dos papéis naturalizados para os quais sempre são convocadas. Considerando que a estrutura político-económica é genderizada em suas bases fundacionais, como sinalizaram Muñoz e Madroño (2011), a linguagem mediática da recessão

Negra e Tasker atribuem ao ideário pós-feminista, que incentiva as práticas baseadas na meritocracia e nas conquistas individuais em detrimento das conquistas e das forças coletivas dos feminismos, uma significativa parcela de responsabilidade nesta representação social das mulheres num contexto de crise. Somado a isso, as autoras sublinham que o discurso institucional frequentemente se apoia na retórica de que não há problemas sistémicos, apenas individuais, sem qualquer rasto ou conexão com forças sociais. Assim, se gera uma «narrativa do impacto económico desigual de género que é contígua com a retórica pós-feminista da atuação e da escolha feminina» (2014: 20).

Esta abordagem converge com a de Alexandre Abreu et al. (2013) acerca do discurso, propagado pelo governo do primeiro-ministro Pedro Passos Coelho, de auto culpabilização dos portugueses pela crise deflagrada em 2008-2009. In: A Crise, a Troika e as Alternativas Urgentes. 
estabelece os mesmos critérios de seleção e de abordagem vistos na narrativa habitual dos media generalistas, operacionalizando, por sua vez, a convencional construção das subjetividades dos sujeitos envolvidos: são discursos que privilegiam os homens como sujeitos da narrativa (da recessão).

Nestes termos, como explicam Negra e Tasker (2014), a cultura popular da recessão, enquanto um dos processos hegemónicos de produção de sentidos, trabalha para o reforço de históricas normas sociais (Magalhães, 2011). No caso concreto das mulheres, a produção de conteúdos mediáticos em torno da crise apoiase em mecanismos discursivos convencionais que em pouco diferem do que é visto na sua prática quotidiana: de uma construção identitária condicionada do género e da orientação de comportamentos adequados à uma certa realidade.

Como sublinhou Joan Scott (1999), as formas pelas quais as sociedades representam o género e o utilizam para articularem as regras das relações sociais ou para atribuir sentido às experiências passam necessariamente pela linguagem. Scott, que questiona, com bases foucaultianas, a naturalização da diferença sexual nas práticas sociais, considera centrais as instituições e estruturas económicas que reproduzem rituais, constituem relacionamentos sociais e conferem à linguagem o estatuto de regulador das formas convencionais de representação.

Aqui, o estudo das diferentes construções de género que emergem da interpretação mediática da cultura da recessão - considerando sobretudo o que é produzido para as mulheres -, é útil para redirecionar o pensamento de forma a considerar a linguagem da crise enquanto um mecanismo de naturalização das normas polarizadas de género. Um exemplo disso é a contradição que se assiste entre a realidade de empobrecimento e de precariedade que assola as mulheres portuguesas e de um discurso institucional, de base pós-feminista, que não contempla a discussão crítica dessa realidade, privilegiando os homens enquanto sujeitos ativos da crise e protagonizando as mulheres no sentido de orientá-las às práticas de consumo.

O discurso é construído intencionalmente na praxis jornalística quotidiana e escolhe as suas palavras não apenas na perspetiva de adequação ao tema tratado, mas também na perspetiva presumida do quadro de conhecimentos a quem se dirige. Logo, a produção deste tipo de conteúdo revela-nos uma construção discursiva dos media que acentua a exclusão das mulheres, nomeadamente do espaço público na tomada de decisões, insere-as em espaços de monopólio masculino e, neste percurso, fortalece uma colagem cultural restrita à esfera da reprodução (2013: 06). A partir deste estatuto regulador da linguagem jornalística sobre a crise, (re)produzida para este público, consolida-se um conjunto de condições de subjugação (Magalhães, 2011) das mulheres onde se verifica a naturalização das desigualdades sociais e de género e a legitimação de toda uma construção social baseada em valores notoriamente patriarcais. Assim, tudo nos leva a crer que quando se fala de crise, homens e mulheres ocupam os discursos dos saberes e das práticas de forma assimétrica. 
Neste contexto, quando se trata de introduzir uma perspectiva mediática na problematização em questão, devemos ter também em conta que o discurso institucional do jornalismo articula-se com a evidência desse ciclo de subrepresentação das mulheres na sociedade contemporânea. Parte desta realidade pode ser atribuída à produção da linguagem jornalística, sobretudo quando voltada aos assuntos do âmbito económico, já que é maioritariamente definida e (re)produzida por homens (Arús et al., 2000; Cabo, 2007; Veiga, 2010). Para além da disparidade de género no ethos da produção das narrativas jornalísticas - e também publicitárias -, como afirmaram Marta Arús et al. (2000), verifica-se que as mulheres raramente são destacadas enquanto fontes das notícias. Essa assimetria, por mais subtil que pareça ser, compromete o árduo processo de diversidade de representações de género no campo mediático, logo, nas mais diferentes culturas, uma vez que ora invisibiliza as mulheres no discurso público, ora estabelece as suas representações sociais - frequentemente associadas às práticas convencionais de género.

\section{Considerações finais}

A compreensão da linguagem económica na atualidade, ligada como se encontra aos media, não deixa de implicar uma problematização social da linguagem da crise: a base androcêntrica que define a conjuntura da recessão económico-financeira. É justamente a partir dessa construção discursiva dos textos jornalísticos (sobretudo dos media generalistas) acerca das mulheres enquanto sujeito e objeto da notícia que o sentido de identidade também vai sendo modulado e lapidado profundamente.

Se o mediático e o simbólico desempenham um papel significativo na construção da identidade e se as narrativas jornalísticas (generalistas ou segmentadas) produzidas voltam-se para representações diminutas do papel das mulheres na crise económica, tudo leva a crer que a atual conjuntura tem condicionado, sobremaneira, a construção de uma identidade particular a estas mulheres: a de ser minoria, silenciada, privada.

Os casos e protagonistas são incontáveis neste cenário de crise e revelam, por sua vez, a natureza construída da identidade de género também para a recessão económica. Nesta sociedade que se redefine sócio e economicamente, as mulheres adquirem múltiplas representações, nomeadamente quando nos referimos à abordagem mediática, que, de acordo com Silveirinha (2004), continuam a construir uma escassa e estereotipada representação das mulheres, sobretudo se considerarmos a abordagem das formas convencionais de representação do masculino e do feminino. Como sublinha Erving Goffman, os estereótipos de género estão de tal maneira incutidos na sociedade, que são claramente assumidos no consumo e em especial na publicidade (1979).

Se são as mulheres as mais afetadas nestes momentos de clivagens e de rup- 
turas político-económicas, especialmente quando se considera a conjuntura de cortes nos investimentos de bem-estar e de proteção social, e o desemprego e a precariedade, porque é que ainda se deparam com o acesso limitado à linguagem pública para exteriorizar as suas experiências enquanto sujeitos sociais? Quais são as implicações desta linguagem jornalística androcêntrica na construção da identidade e da subjetividade das mulheres?

Diferentes experiências levam a diferentes relações com a linguagem, logo, a construção subjetiva das mulheres a partir do discurso da crise, onde estão diferentemente posicionadas na estrutura sócio-laboral, revela-se convergida com a sua representação social: sub-representada, marginalizada e estereotipada. O que nos leva a crer, por ora, é que tanto a disparidade de género no seio da produção jornalística, como o discurso de caráter androcêntrico são apenas algumas das componentes de um processo ainda mais complexo dos mecanismos de controlo político-económico e social da linguagem que se revela profundamente marcado pelo género, onde as mulheres continuam a ter um estatuto social inferior relativamente aos homens.

Ainda neste âmbito, interpretar a cultura da recessão com base nos estudos mediáticos também possibilita uma análise de como a opinião pública tem sido formada. Nestes termos, ao repensar a posição assimétrica ocupada pelas mulheres no espaço público e na construção das decisões sociais, a formação da opinião pública em torno dos assuntos económicos se dará, por via de regra, pelas mesmas noções hegemónicas binaristas que definem a representação social de cada grupo.

No fundo, importa refletir sobre as relações (re)criadas na linguagem e a sua experiência quotidiana com os seus agentes envolvidos, os quais respondem a uma estrutura histórica e ontologicamente patriarcal e androcêntrica, em que a invisibilidade das mulheres tanto pode ser observada na sua produção como enquanto sujeito do discurso. Neste contexto, a linguagem, tal como hoje se encontra ligada ao jornalismo de caráter neoliberal, vem contribuindo para uma representação social que se coaduna cada vez mais com o sistema político-económico em vigor, inclusivamente se se tem em conta a temática da crise. Assim, o debate sobre as diversas representações sociais das mulheres na linguagem (mediática) sobre a crise perpassa por vários aspectos que têm intensificado as normas polarizadas de género e sedimentado os papéis e funções das mulheres, perpetuando, assim, um ciclo.

\section{Referências Bibliográficas}

Arús, Marta et al. (2000), El Sexo de la Noticia: Reflexiones sobre el género en la información y recomendaciones de estilo, Barcelona, Icaria.

Biroli, Flávia (2010), «Mulheres e política nas notícias. Estereótipos de género e competência política», Revista Crítica de Ciências Sociais 90, 45-69.

Bordo, Susan (1993), Unbearable Weight. Feminism, western culture and the body, Berkley \& Los Angeles, University of California Press. 
Casaca, Sara Falcão (2012), «Mercado de trabalho, flexibilidade e relações de género: tendências recentes», in Sara Falcão Casaca (org.), Mudanças Laborais e Relações de Género: Novos vetores de (des)igualdade, Lisboa, Almedina, 09-50.

Ferreira, Virgínia (2014), «Employment and Austerity: Changing welfare and gender regimes in Portugal», in Maria Karamessini; Jill Rubery (orgs.), Women and Austerity: The Economic Crisis and the Future for Gender Equality, New York, Routledge, 207-227.

Fraser, Nancy (2009), «O Feminismo, o Capitalismo e a Astúcia da História», Contribuições do Pensamento Feminista para as Ciências Sociais 14(2), 11-33.

Gauntlet, David (2004), Media, Gender and Identity: an Introduction, London, Routledge.

Goffman, Erving (1979), Gender Advertisements: Studies in the Anthropology of Visual Communication 3:2 (1976) [rpt. as Gender Advertisements, 1979], 69-154.

Karamessini, Maria (2014), «Women's vulnerability to recession and austerity: a different crisis, a different context», in Maria Karamessini; Jill Rubery (orgs.), Women and Austerity: The Economic Crisis and the Future for Gender Equality, New York, Routledge, 03-16.

Lemieux, Cyril (2000), Mauvaise Presse: Une sociologie compréhensive du travail journalistique et de ses critiques, Paris, Éditions Métailié.

Magalhães, Sara Isabel Almeida (2011), Como ser uma Ragazza: Discursos de sexualidade numa revista para raparigas adolescentes, Trabalho de Tese de conclusão do Doutoramento em Psicologia da Educação, Braga, Universidade do Minho.

Muñoz, Lina Gálves; Madroño, Paula Rodríguez (2011), «La desigualdade de género en las crisis económicas», Investigaciones Feministas 2, 113-132.

Negra, Diane; Tasker, Yvonne (2014), Gendering the Recession: Media and Culture in a Age of Austerity, London, Duke University Press.

Reinharz, Shulamit (1992), «Feminist Content Analysis», in Feminist Methods in Social Research, 145-163.

Rubery, Jill (2014), «From 'women and recession' to 'women and austerity': a frameworks for analysis», in Maria Karamessini; Jill Rubery (orgs.), Women and Austerity: The Economic Crisis and the Future for Gender Equality, New York, Routledge, 17-36.

Scott, Joan (1999), Gender and the Politics of History, New York, Columbia University Press.

Silveirinha, Maria João (2004), As Mulheres e os Media, Lisboa, Livros Horizonte.

Tuchman, Gaye (2009), «Media, Género, Nichos», Media \& Jornalismo 15, 15-24.

União Mulheres Alternativa e Resposta (2013), Relatório da Campanha Feminista Anti-Austeritária, apresentado no I Encontro Nacional da Iniciativa por uma Auditoria Cidadã «As crises não pagam dívidas»

Walby, Sylvia (2011), The Future of Feminism, Cambridge, Polity.

Juliana Mello Souza. Doutoranda no programa Linguagens e Heterodoxias: História, Poética e Práticas Sociais do Centro de Estudos Sociais da Universidade de Coimbra. Licenciada em Ciências da Comunicação e Mestre em Jornalismo e Estudos Mediáticos pela Universidade Nova de Lisboa. Bolseira pela FCT no âmbito da Bolsa de Doutoramento com a referência SFRH/BD/72415/2010.

Endereço: Juliana Mello Souza, CES, Colégio de S. Jerónimo - Largo D. Dinis - Apartado 3087, 3000-995 Coimbra, Portugal. jmellosouza@gmail.com 